\title{
Pharmacokinetics of Imipenem in Critically III Patients with Life-threatening Severe Infections During Support with Extracorporeal Membrane Oxygenation
}

\author{
Sutep Jaruratanasirikul ${ }^{1}$. Veerapong Vattanavanit ${ }^{1} \cdot$ Maseetoh Samaeng $^{1} \cdot$ Monchana Nawakitrangsan $^{1}$. \\ Somchai Sriwiriyajan ${ }^{2}$
}

Published online: 23 May 2019

(c) Springer Nature Switzerland AG 2019

\begin{abstract}
Background Extracorporeal membrane oxygenation (ECMO) has become increasingly used for lifesaving respiratory and/or cardiac failure support in critically ill patients, including those with life-threatening severe infections. This cardiopulmonary bypass device has been shown to enhance the profound pathophysiological changes in this patient population, resulting in an alteration of the pharmacokinetics of antimicrobial agents.

Objective The aim of this study was to determine the effect of ECMO on the pharmacokinetics of imipenem in critically ill patients supported by this cardiopulmonary bypass device.

Methods The study was conducted in critically ill patients with respiratory and/or cardiac failure and severe infections who were supported by ECMO. All patients received a 1-h infusion of $0.5 \mathrm{~g}$ of imipenem every $6 \mathrm{~h}$ and imipenem pharmacokinetics studies were carried out on the fourth dose of drug administration.

Results Ten patients were enrolled in this study. The pharmacokinetics parameters of imipenem were found to be highly variable. The volume of distribution, total clearance, elimination half-life and the area under the concentration-time curve between 0 and $6 \mathrm{~h}$ were $33.38 \pm 13.89 \mathrm{~L}, 9.99 \pm 10.47 \mathrm{~L} / \mathrm{h}, 12.01 \pm 29.63 \mathrm{~h}$ and $88.93 \pm 54.07 \mathrm{mg} \bullet \mathrm{h} / \mathrm{L}$, respectively.

Conclusions Pathophysiological changes in critically ill patients with severe infections during support with ECMO had a greater impact on altered pharmacokinetic patterns of imipenem than those that occur in critically ill patients without ECMO support. Therefore, the largest licensed dose, $1 \mathrm{~g}$ every $6 \mathrm{~h}$, of imipenem, may be required to maintain adequate drug concentrations to achieve the pharmacokinetic/pharmacodynamic targets for effective antimicrobial therapy in this patient population.
\end{abstract}

\section{Key Points}

Pathophysiological changes in critically ill patients with severe infections during support with ECMO had a greater impact on altered pharmacokinetic patterns of imipenem than those that occur in critically ill patients without ECMO support.

The largest licensed dosage of imipenem may be required to maintain adequate drug concentrations in this patient population.

Sutep Jaruratanasirikul

jasutep@medicine.psu.ac.th

1 Department of Medicine, Faculty of Medicine, Prince of Songkla University, Hat Yai, Songkla 90110, Thailand

2 Department of Pharmacology, Faculty of Science, Prince of Songkla University, Hat Yai, Songkla 90110, Thailand

\section{Introduction}

Extracorporeal membrane oxygenation (ECMO), a cardiopulmonary bypass device, has been increasingly used in critical conditions for severely ill patients in intensive care units (ICU). ECMO is a temporal lifesaving system that can provide partial or complete support for patients with respiratory and/or cardiac failure for whom conventional treatments have been unsuccessful [1,2]. One of the big challenges for physicians who take care of these patients is that ECMO has been shown to enhance the profound pathophysiological changes in these critical patients, leading to alterations in the pharmacokinetics of many therapeutic drugs, including increased volume of distribution $\left(V_{\mathrm{d}}\right)$ and decreased total clearance (CL) of various important antimicrobial agents for the treatment of severe infections [1-4]. However, studies on the impact of ECMO on the pharmacokinetics of antimicrobial agents have usually been done in pediatric populations, resulting in difficulties 
extrapolating the data for use in adult populations due to significant differences in absorption, distribution, metabolism and excretion of therapeutic drugs between these two populations [1-3].

Imipenem, a hydrophilic $\beta$-lactam antibiotic, has a relatively low $V_{\mathrm{d}}$ at steady state and has been found to be $<10$ to $20 \%$ bound to proteins. This agent has been found to be eliminated by renal clearance, primarily via glomerular filtration and tubular secretion, with an elimination half-

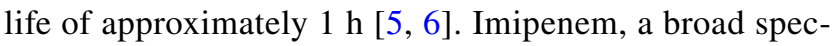
trum carbapenem, is commonly prescribed for treatment of nosocomial infections involving highly resistant pathogens $[5,6]$. In common with other $\beta$-lactams, this drug exhibits primarily time-dependent antimicrobial activity, and the pharmacodynamic index that best correlates with antimicrobial activity is the exposure time during which the free drug concentration remains above the minimal inhibitory concentration (MIC) $\left(f \mathrm{~T}_{>\mathrm{MIC}}\right)$ of the pathogen $[7,8]$. However, to date, there have been limited pharmacokinetic studies of antimicrobial agents, especially imipenem, in these critical conditions [1,9]. Therefore, the aim of this study was to determine the effect of ECMO on the pharmacokinetics of imipenem in critically ill adult patients supported by this cardiopulmonary bypass device.

\section{Patients and Methods}

\subsection{Study Population and Design}

The study was conducted in critically ill patients with respiratory and/or cardiac failure and severe infections admitted into the ICU of Songklanagarind Hospital, the largest tertiary care center in southern Thailand, between December 2015 and February 2019. Included patients were aged $\geq 18$ years with cardiopulmonary failure and were supported by ECMO receiving a 1-h infusion of $0.5 \mathrm{~g}$ imipenem/cilastatin diluted in $100 \mathrm{~mL}$ of normal saline solution, delivered via infusion pump at a constant flow rate, every $6 \mathrm{~h}$ for the treatment of severe infections for 14 days. The protocol for the study was approved by the Ethics Committee of Songklanagarind Hospital, and written informed consent was obtained from each subject's legally acceptable representative before enrollment.

\subsection{Drugs and Chemicals}

Imipenem/cilastatin $\left(\right.$ Tienam $^{\circledR}$ ) was purchased from MSD, Thailand. Imipenem standard powder was purchased from the U.S. Pharmacopeia (Rockville, MD, USA) as pure powder. All the solvents were of high-performance liquid chromatography (HPLC) grade.

\subsection{Blood Sampling}

The imipenem pharmacokinetic studies were carried out during administration of the fourth dose of imipenem (18-24 $\mathrm{h}$ after the start of the regimen) in the ICU with the air conditioning at an average temperature of $25^{\circ} \mathrm{C}$. Blood samples $(\sim 3 \mathrm{~mL})$ were obtained from a heparinized intravascular catheter (on the side of the body opposite that used for administration of the study drug) by direct venipuncture at the following times: before (time zero) and $0.25,0.5,0.75,1,2,3,4,5$ and $6 \mathrm{~h}$ after the fourth dose of each regimen. The blood samples were added to a heparinized tube and centrifuged at $1000 \mathrm{~g}$ for $10 \mathrm{~min}$ not later than 15 min after collection. An equal volume of stabilizing solution (0.5 M MOPS/water/ethylene glycol, 2:1:1, $\mathrm{v} / \mathrm{v} / \mathrm{v}$ ) was added to each plasma sample [10,11], which was then vortexed and stored at $-80{ }^{\circ} \mathrm{C}$ until analysis within 1 week.

\subsection{Imipenem Assay}

This assay was used for measuring imipenem concentrations only, not for cilastatin concentrations. The concentrations of imipenem were determined by reverse-phase HPLC. The samples were prepared by the method of Garcia-Capdevila et al. [10]. Briefly, $250 \mu \mathrm{L}$ of the stabilizing solution was added to $250 \mu \mathrm{L}$ of the sample. The mixture was then subjected to ultrafiltration, using an Ultrafree ${ }^{\circledR}$-MC Centrifugal Filter Unit, for $10 \mathrm{~min}$ at $6000 \mathrm{~g}$. An aliquot of the sample $(50 \mu \mathrm{L})$ was injected onto a Nova-Pak C18 column (Waters Associates) using an automated injection (Waters e2695 Plus autosampler; Waters associates, Milford, MA, USA). The mobile phase used $0.2 \mathrm{M}$ borate buffer, $\mathrm{pH} 7.2$, at a flow rate of $1 \mathrm{~mL} /$ min. The column effluent was monitored by a photodiode array detector (Waters 2996; Waters associates, Milford, MA, USA) at $300 \mathrm{~nm}$. The peaks were recorded and integrated on a Waters 746 Data Module (Waters Associates). The validation tests were found to be within acceptable limits as per the 2013 US Food and Drug Administration Guidance on Bioanalytical Method Validation [12]. The lower limit of quantitation (LLOQ) of imipenem was $0.25 \mathrm{mg} / \mathrm{L}$. This assay was found to be selective as no interference was found with biological matrix on six individual blank plasma. The method was found to be linear in the concentration range of $0.25-100 \mathrm{mg} / \mathrm{L}$ by following the regression equation $y=13558 X+2303.3$ with correlation coefficients $\left(r^{2}\right)$ of 0.9997 . The intra-assay reproducibility values characterized by coefficients of variation $(\mathrm{CVs})$ were $0.19 \%, 0.71 \%$ and $0.11 \%$ for samples containing 0.75, 20 and $75 \mathrm{mg} / \mathrm{L}$, respectively. For intra-assay, the relative biases were $0.44 \%, 1.57 \%$, and $0.36 \%$ for samples 
containing $0.75,20$, and $75 \mathrm{mg} / \mathrm{L}$, respectively. The interassay reproducibility precision values, calculated by $\mathrm{CVs}$, were $0.39 \%, 1.63 \%$ and $0.23 \%$ for samples containing 0.75 , 20 and $0.75 \mathrm{mg} / \mathrm{L}$, respectively. For inter-assay, the relative biases were $0.38 \%, 2.47 \%$, and $0.33 \%$ for samples containing $0.75,20$, and $75 \mathrm{mg} / \mathrm{L}$, respectively. A short-term stability study showed that at room temperature for sample containing 0.75 and $75 \mathrm{mg} / \mathrm{L}$, the concentrations of imipenem losses were $<1 \%$ for at least $1 \mathrm{~h}$. A long-term stability study showed that at $-80{ }^{\circ} \mathrm{C}$ for sample containing 0.75 and $75 \mathrm{mg} / \mathrm{L}$, the concentrations of imipenem losses were $<5 \%$ for at least 14 days. All plasma samples were tested within 7 days of collection and analyzed within $1 \mathrm{~h}$ after thawing process. The recovery values were $98.67 \pm$ $0.57 \%, 94.71 \pm 2.00 \%$ and $102.70 \pm 1.15 \%$ for sample containing $0.75,20$, and $75 \mathrm{mg} / \mathrm{L}$, respectively. Carry-over testing was performed, but no-carry over was found.

\subsection{Pharmacokinetics and Statistical Analysis}

Pharmacokinetics analysis was conducted using two-compartmental pharmacokinetic analysis. The maximum plasma concentrations $\left(C_{\max }\right)$, minimum plasma concentrations $\left(C_{\min }\right)$, area under the concentration-time curve between 0 and $6 \mathrm{~h}\left(\mathrm{AUC}_{0-6}\right)$, distribution half-life $\left(t_{1 / 2 \alpha}\right)$, elimination half-life $\left(t_{1 / 2 \beta}\right), V_{\mathrm{d}}, \mathrm{CLs}$, the rate at which the drug leaves the system from the central compartment $\left(k_{10}\right)$, intercompartment transfer rate constant from compartment X1 to $\mathrm{X} 2\left(k_{12}\right)$ and intercompartment transfer rate constant from compartment $\mathrm{X} 2$ to $\mathrm{X} 1\left(k_{21}\right)$ were determined using WinNonlin Version 1.1 (Scientific Consulting Inc., NC, USA). The results were expressed as mean \pm standard deviation. The relationships between the pharmacokinetic parameters and clinical covariates, including sex, age, body-weight, body mass index, serum albumin, creatinine clearance $\left(\mathrm{CL}_{\mathrm{Cr}}\right)$, acute physiology and chronic health evaluation II (APACHE II) score, sepsis-related organic failure assessment (SOFA) score, fluid balance, concomitant medications and flow rate of ECMO circuit were analyzed. The mean pharmacokinetic parameters of imipenem of all patients were compared to values obtained from critically ill patients without ECMO from our 3 previous studies in 18 critically ill patients [13-15] and to values obtained from our previous study in 8 healthy volunteers [16] at the same dosage regimen, using the $t$ test. For the critically ill patients without ECMO group, the two-compartmental pharmacokinetic analysis was conducted using the data from our 3 previous studies in 13 critically ill patients with VAP $[13,14]$ and 5 serious bacteremia in immunocompromised patients with febrile neutropenia [15]. The $p$ values of $<0.05$ were considered to be significant.

\section{Results}

The demographic data of all patients are shown in Table 1 and the demographic data of the critically ill patients without ECMO (the control group) are shown in Table 2. The ECMO characteristics of all patients are shown in Table 3 . The mean imipenem pharmacokinetic parameters are shown in Table 4. The individual plasma concentration-time profiles of imipenem of all patients are shown in Fig. 1. The plasma concentration values of imipenem of all patients characterized by CVs were $76.42 \%, 50.32 \%, 66.15 \%, 67.60 \%, 61.36 \%$, $46.68 \%, 48.71 \%, 58.86 \%, 71.46 \%$ and $71.62 \%$ at the following times: before (time zero) and $0.25,0.5,0.75,1,2,3$, 4,5 and $6 \mathrm{~h}$ after the fourth dose of each regimen, respectively. The $V_{\mathrm{d}}, \mathrm{CL}, t_{1 / 2 \beta}$ and $\mathrm{AUC}_{0-6}$ were $33.38 \pm 13.89 \mathrm{~L}$, $9.99 \pm 10.47 \mathrm{~L} / \mathrm{h}, 12.01 \pm 29.63 \mathrm{~h}$ and $88.93 \pm 54.07 \mathrm{mg} \bullet \mathrm{h} / \mathrm{L}$, respectively. The $\mathrm{CL}_{\mathrm{Cr}}$ as estimated by the Cockcroft and Gault equation and APACHE II scores were significant covariates describing the CL and $k_{10}$ of imipenem, whereas SOFA score was significant covariate explaining $t_{1 / 2 \beta}, k_{10}$, and $C_{\text {min }}$, of imipenem. There were no significant covariates that explained the $V_{\mathrm{d}}$ of imipenem. Among the ten enrolled patients, the plasma concentrations at $2.4 \mathrm{~h}$ after the fourth dose of imipenem of all patients were $\geq 2 \mathrm{mg} / \mathrm{L}$ and nine patients were $\geq 4 \mathrm{mg} / \mathrm{L}$, while, the trough concentrations of imipenem in eight patients were $\geq 2 \mathrm{mg} / \mathrm{L}$ and four patients were $\geq 4 \mathrm{mg} / \mathrm{L}$.

\section{Discussion}

Alteration of pathophysiological conditions in critically ill patients with life-threatening severe infections causes pharmacokinetic changes, including $V_{\mathrm{d}}$ and CL for antibiotics. An extravasation of a large volume of fluid resuscitation into extravascular spaces, associated with endothelial damage and subsequently enhanced capillary permeability, results in a larger $V_{\mathrm{d}}$ than the values obtained from healthy volunteers. In addition, the initial hyperdynamic state of severe infection is associated with a high cardiac output and increased renal blood flow, resulting in enhancement of renal clearance of antimicrobial agents. On the other hand, however, decreased renal clearance with end-organ dysfunction may occur with severe infections and septic shock in late-state disease [17-19]. In critically ill patients with severe sepsis being supported by ECMO, the enhancement of pharmacokinetic changes of antimicrobial agents can occur as a result of the patient's altered pathophysiological condition by this life-support modality and the extent of drug loss due to direct extraction by the circuit which depends primarily on the physicochemical properties of the antibiotics and the circuit component materials $[1-3,20]$. However, most 


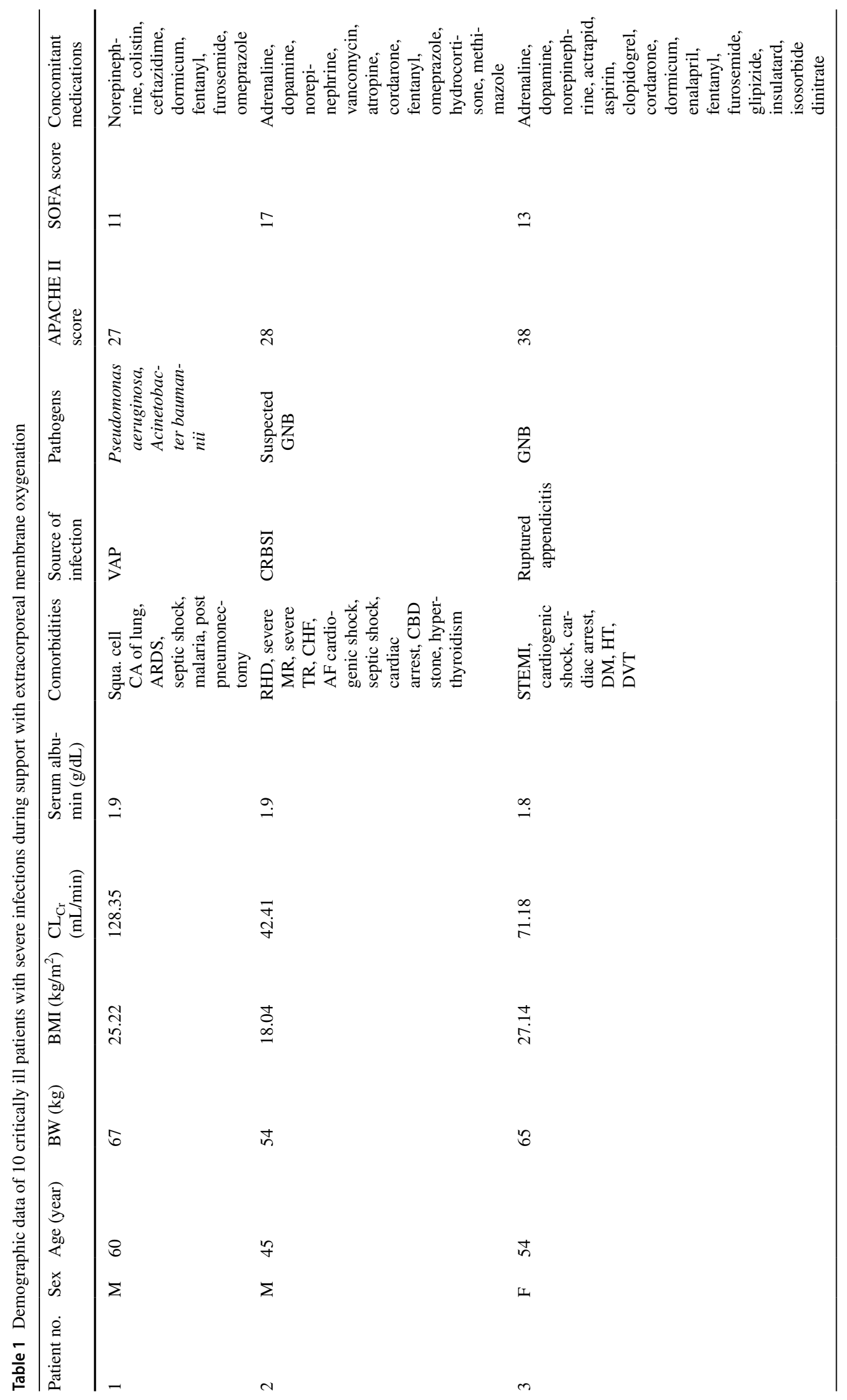




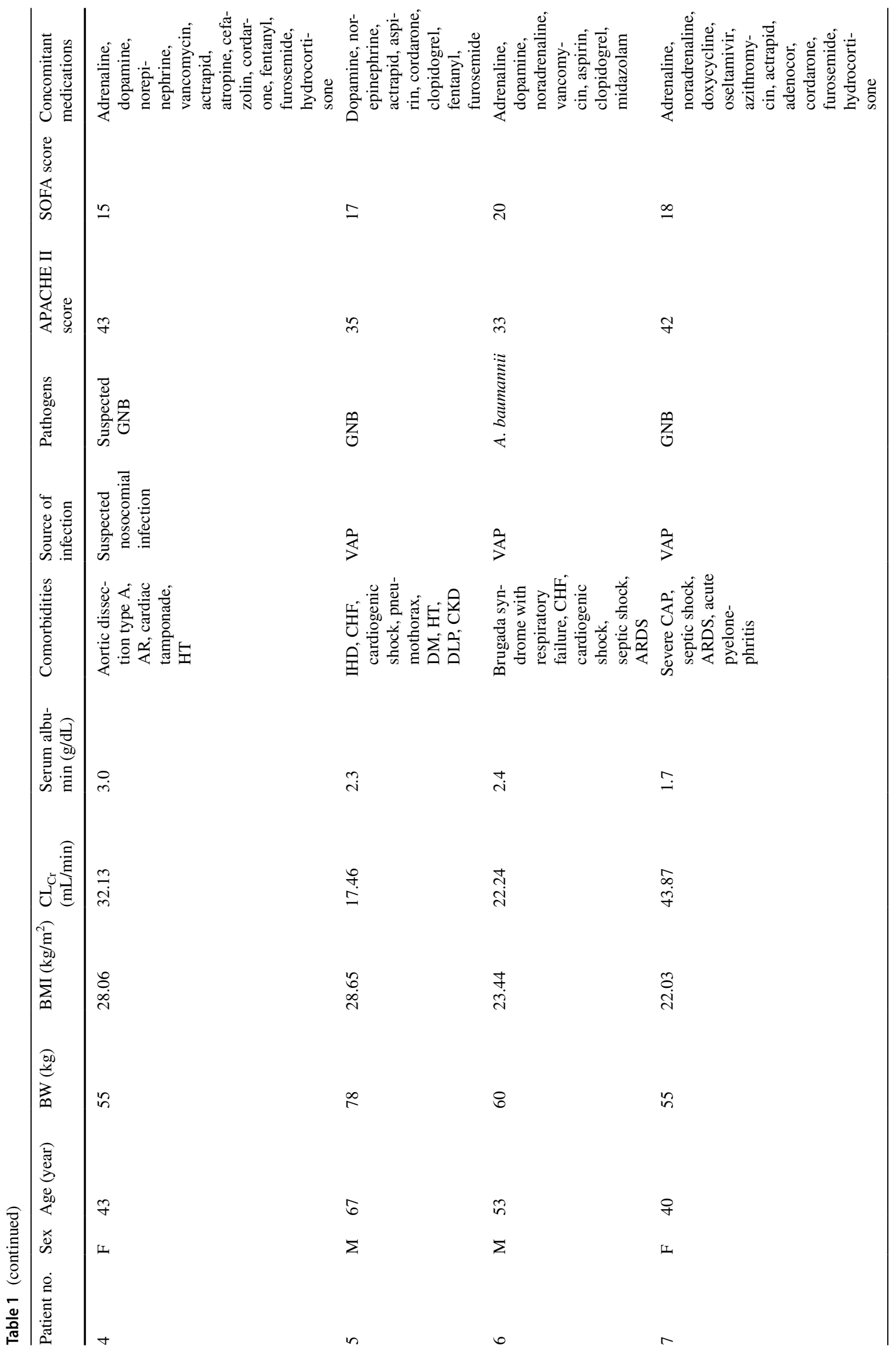




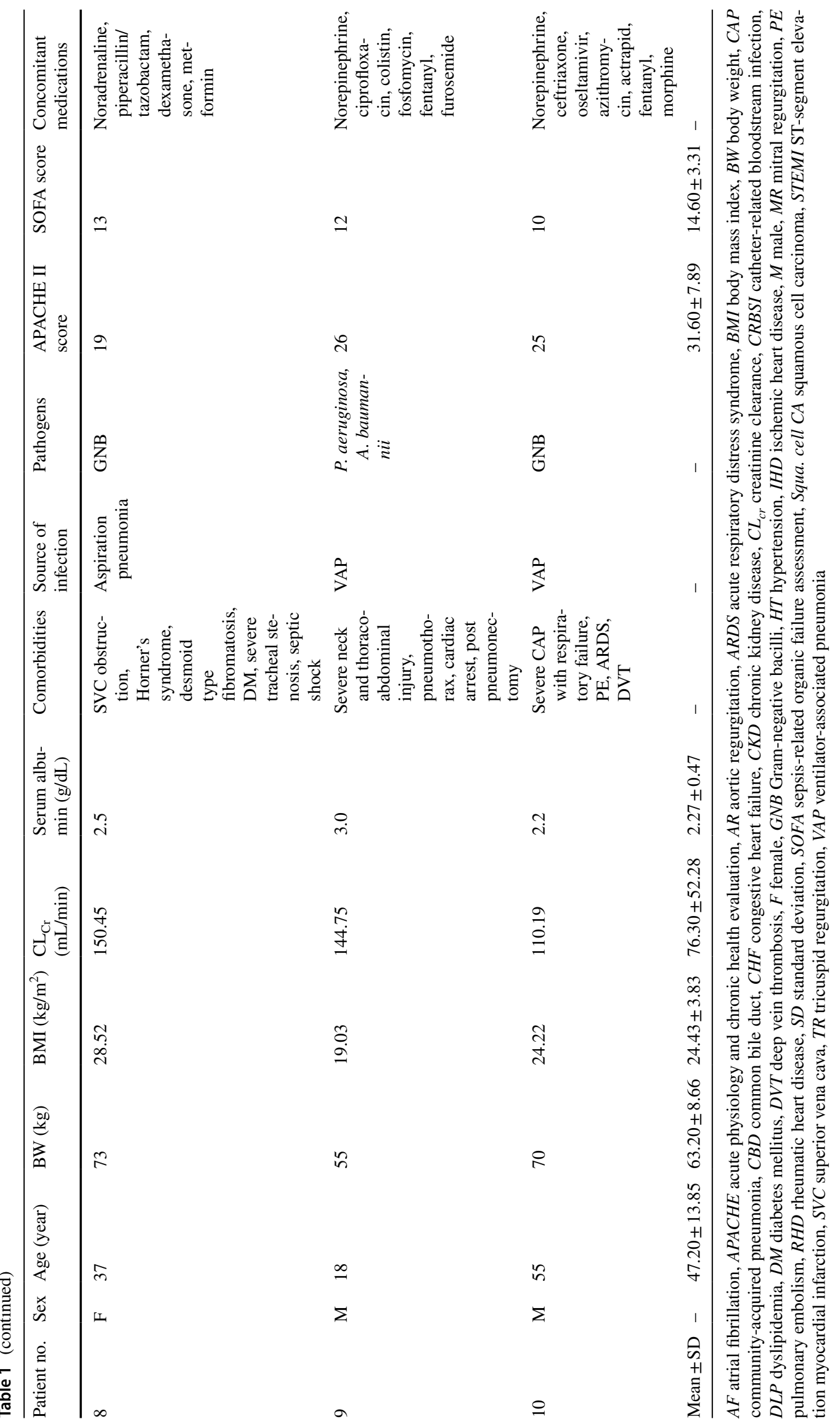




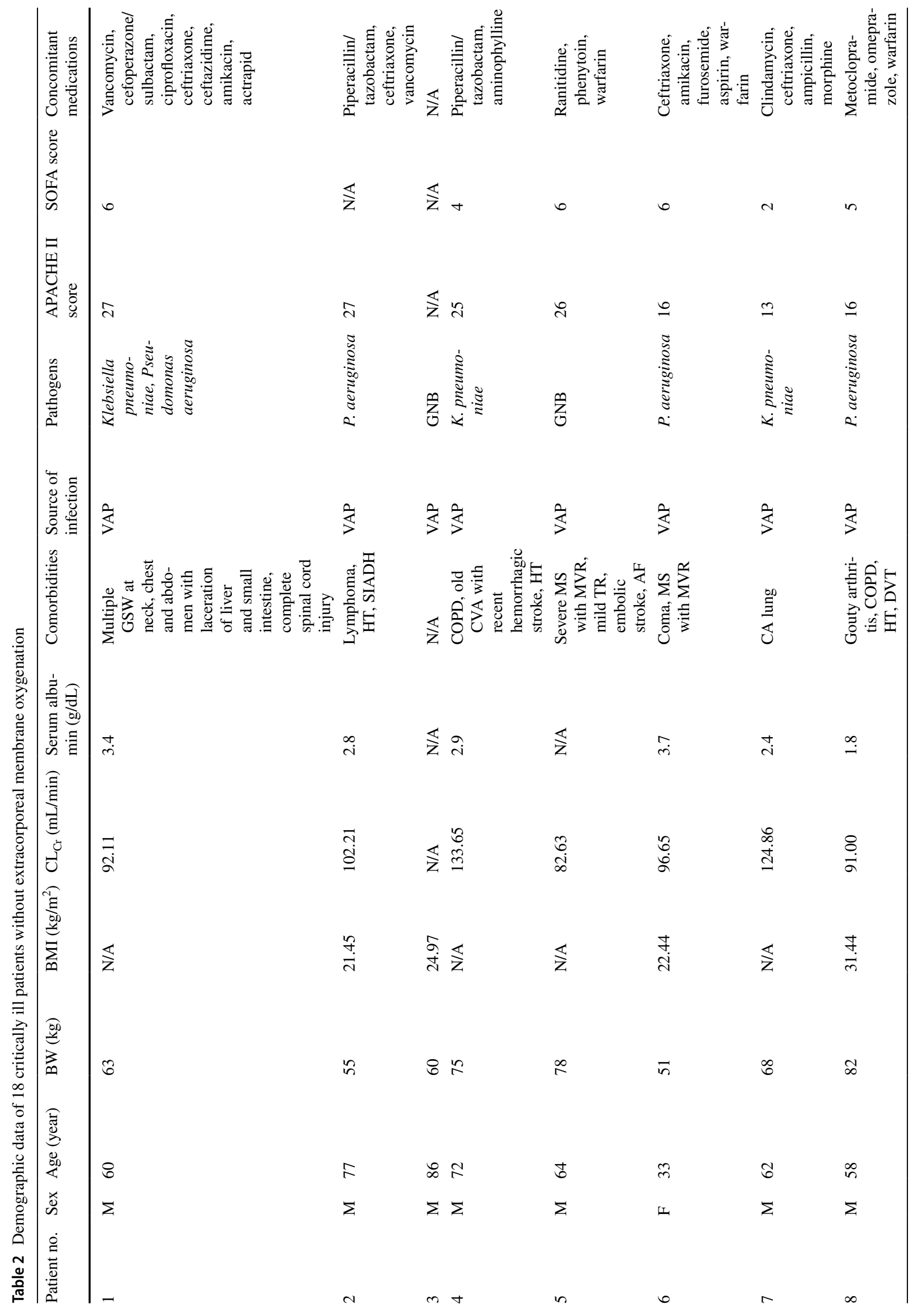




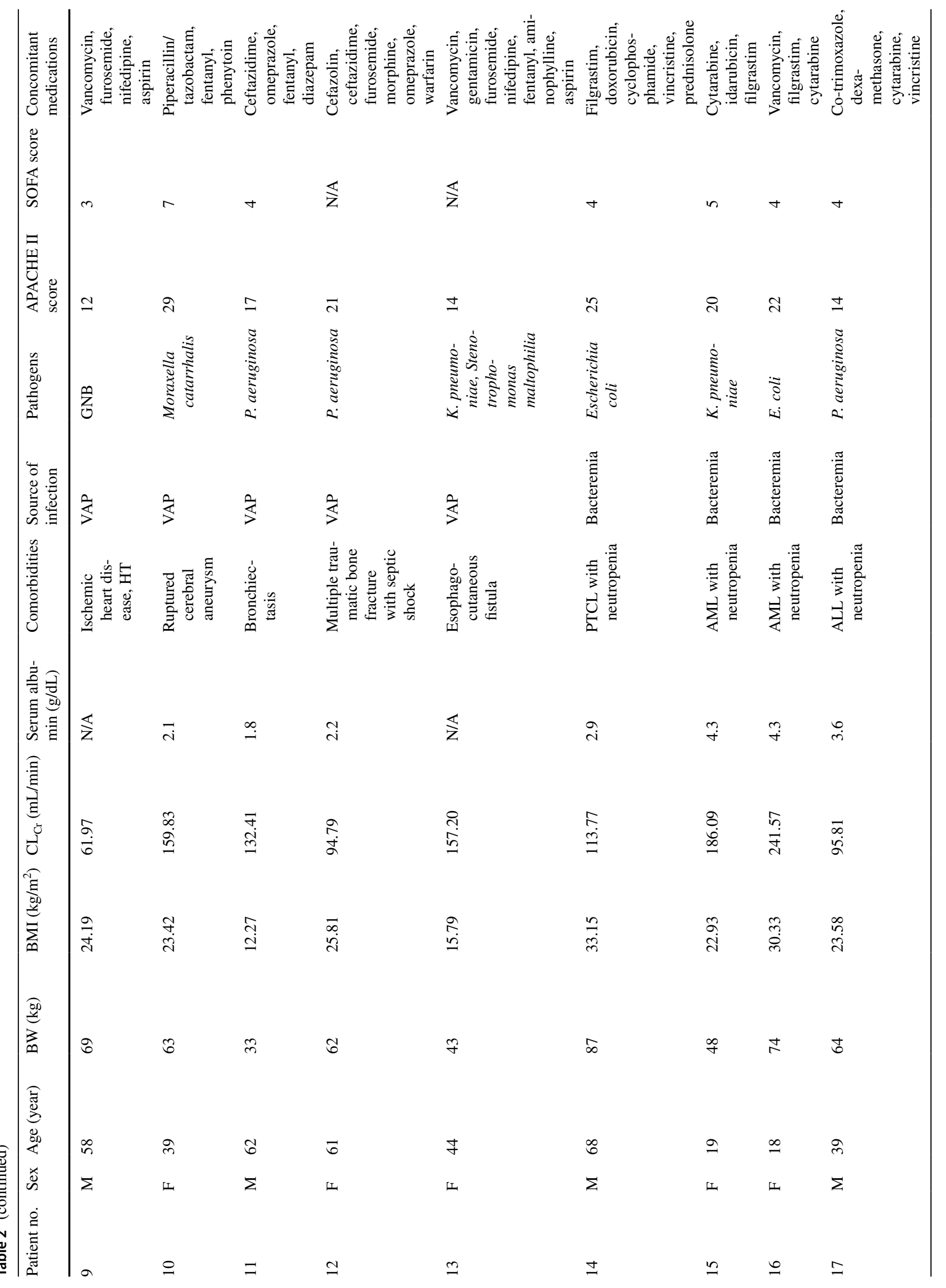




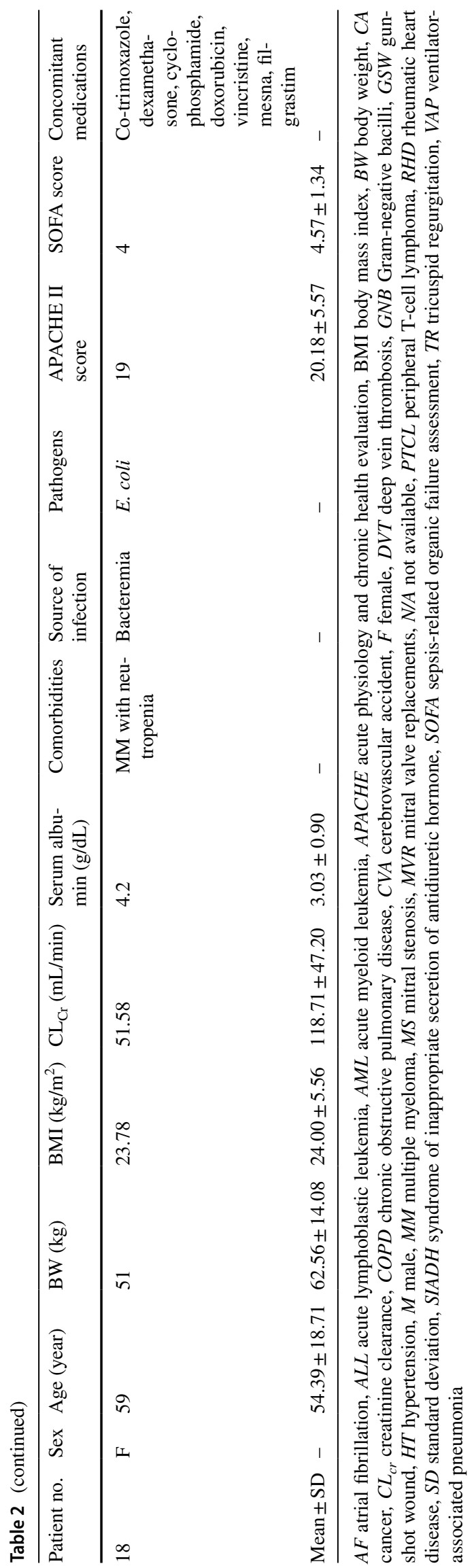

of the previous studies supporting these findings in critical settings with ECMO support, were conducted in neonatal populations [1,2]. Several pharmacokinetic studies in adult populations have reported that $V_{\mathrm{d}}$ and CL were unchanged when compared to values obtained from critically ill patients without ECMO [1, 21, 22]. Ex vivo studies have demonstrated that highly lipophilic and protein-bound antibiotics are prone to increased sequestration when subjected to an ECMO circuit. However, imipenem has been found to be a hydrophilic and low protein-binding antimicrobial agent [20]. Therefore, the degree of extraction of imipenem by the circuit may not be markedly high when compared to the highly lipophilic and high protein-bound antimicrobial agents. In addition, imipenem in concentrated solutions has been found to have the greatest instability among the $\beta$-lactam antibiotics. A previous study showed that imipenem remained $90 \%$ stable for $3 \mathrm{~h}$ and $30 \mathrm{~min}$ at $25{ }^{\circ} \mathrm{C}$ and was degraded by up to $25 \%$ within $24 \mathrm{~h}$, at that temperature [23]. Therefore, the stability of imipenem is an important consideration if this agent is being considered for the treatment of severe sepsis in patients being supported by ECMO. Our study found that the plasma concentrations of imipenem characterized by CVs were high (range, $46.68 \%$ to $76.42 \%$ ), resulting in highly variable pharmacokinetic parameters of imipenem. This finding may be due to other variabilities in hypoalbuminemia, renal function, positive fluid balance and the use of inotropic drugs from differing severe comorbidities across the patient population. The mean values of $V_{\mathrm{d}}$ and $t_{1 / 2 \beta}$ were $0.54 \pm 0.25 \mathrm{~L} / \mathrm{kg}$ and $12.01 \pm 29.63 \mathrm{~h}$, which were $>3$-fold greater than the value obtained from healthy volunteers, but the mean values of CL were not statistically significantly different [16].

A previous case report of trough concentrations of $1 \mathrm{~g}$ every $6 \mathrm{~h}$ of imipenem in two lung transplant recipients supported with ECMO found the concentrations to be highly variable, 11.3 and $2.7 \mathrm{mg} / \mathrm{L}$, both of which were higher than the MICs of the two isolated microorganisms [9]. The current study was conducted to determine the effect of ECMO on the pharmacokinetics of imipenem in very critically ill patients with life-threatening severe Gram-negative bacilli infections, including Pseudomonas aeruginosa and Acinetobacter baumannii. The altered pharmacokinetics of imipenem in the current study were different from previous pharmacokinetic studies in critically ill patients without ECMO support [13-15]. In the current study, the $V_{\mathrm{d}}$ of imipenem was greater and the $C L$ of imipenem was lower than the values obtained from patients without ECMO support [13-15]. A possible explanation for the pharmacokinetic changes in this study would be that all recruited patients had a critical illness complicated by a life-threatening severe infection and half of them had septic shock, resulting in a positive fluid balance in all patients from receiving large volumes of fluid for management of shock and maintaining 
Table 3 Characteristics of extracorporeal membrane oxygenation (ECMO) in 10 critically ill patients with severe infections during support with extracorporeal membrane oxygenation

\begin{tabular}{|c|c|c|c|c|c|c|}
\hline Patient no. & Type & Duration (d) & Indication & Flow rate $(\mathrm{L} / \mathrm{min})$ & Fluid balance (L) & Outcome \\
\hline 1 & VV & 22.00 & Respiratory failure & 3.5 & 2.84 & Death \\
\hline 2 & VA & 6.25 & Cardiac failure & 4.70 & 9.07 & Death \\
\hline 3 & VA & 7.04 & Cardiac failure & 3.40 & 1.66 & Clinical improvement \\
\hline 4 & VA & 1.71 & Cardiac failure & 1.50 & 2.90 & Death \\
\hline 5 & VA & 3.46 & Respiratory and cardiac failure & 2.70 & 3.75 & Death \\
\hline 6 & VA & 10.58 & Respiratory and cardiac failure & 3.50 & 5.30 & Death \\
\hline 7 & VA & 2.00 & Respiratory and cardiac failure & 3.50 & 11.51 & Death \\
\hline 8 & VV & 5.04 & Respiratory failure & 1.80 & 5.73 & Death \\
\hline 9 & VV & 6.92 & Respiratory failure & 2.90 & 5.43 & Clinical improvement \\
\hline 10 & VV & 12.54 & Respiratory failure & 2.40 & 4.75 & Clinical improvement \\
\hline Mean \pm SD & - & $7.75 \pm 6.08$ & - & $2.99 \pm 0.94$ & $5.29 \pm 3.00$ & - \\
\hline
\end{tabular}

$d$ day(s), $h$ hour(s), fluid balance fluid intake minus fluid output for $48 \mathrm{~h}$ during administration of imipenem, $S D$ standard deviation, $V A$ venoarterial ECMO, $V V$ venovenous ECMO

Table 4 Pharmacokinetic parameters (mean \pm SD) of imipenem in 10 critically ill patients with severe infections during support with extracorporeal membrane oxygenation (ECMO) compared with 18 critically ill patients without ECMO and 8 healthy volunteers

\begin{tabular}{|c|c|c|c|}
\hline Pharmacokinetic parameter & Patients with ECMO & Patients without $\mathrm{ECMO}^{\mathrm{b}}$ & Healthy volunteers ${ }^{\mathrm{c}}$ \\
\hline$C_{\max }(\mathrm{mg} / \mathrm{L})$ & $24.37 \pm 14.45$ & $15.86 \pm 5.77$ & $48.43 \pm 5.89^{\mathrm{a}}$ \\
\hline$C_{\min }(\mathrm{mg} / \mathrm{L})$ & $4.78 \pm 3.78$ & $0.69 \pm 0.79^{\mathrm{a}}$ & $0.62 \pm 0.31^{\mathrm{a}}$ \\
\hline $\mathrm{AUC}_{0-6}(\mathrm{mg} \cdot \mathrm{h} / \mathrm{L})$ & $88.93 \pm 54.07$ & $28.17 \pm 13.92^{\mathrm{a}}$ & - \\
\hline$t_{1 / 2 \alpha}(\mathrm{h})$ & $0.92 \pm 2.47$ & $0.28 \pm 0.31$ & - \\
\hline$t_{1 / 2 \beta}(\mathrm{h})$ & $12.01 \pm 29.63$ & $7.37 \pm 24.31$ & $1.32 \pm 0.27^{\mathrm{a}}$ \\
\hline$V_{\mathrm{d}}:$ total $(\mathrm{L})$ & $33.38 \pm 13.89$ & $21.32 \pm 15.01^{\mathrm{a}}$ & $9.41 \pm 1.44^{\mathrm{a}}$ \\
\hline$V_{\mathrm{d}}:$ per body weight $(\mathrm{L} / \mathrm{kg})$ & $0.54 \pm 0.25$ & $0.39 \pm 0.45$ & $0.16 \pm 0.02^{\mathrm{a}}$ \\
\hline CL: total $(\mathrm{L} / \mathrm{h})$ & $9.99 \pm 10.47$ & $21.49 \pm 9.57^{\mathrm{a}}$ & $7.95 \pm 1.04$ \\
\hline CL: per body weight $(\mathrm{L} / \mathrm{h} \cdot \mathrm{kg})$ & $0.15 \pm 0.14$ & $0.39 \pm 0.30^{\mathrm{a}}$ & $0.14 \pm 0.02$ \\
\hline$k_{10}\left(\mathrm{~h}^{-1}\right)$ & $1.90 \pm 2.15$ & $1.36 \pm 1.08$ & $0.56 \pm 0.18$ \\
\hline$k_{12}\left(\mathrm{~h}^{-1}\right)$ & $7.16 \pm 6.39$ & $4.47 \pm 6.27$ & - \\
\hline$k_{21}\left(\mathrm{~h}^{-1}\right)$ & $1.40 \pm 0.98$ & $2.71 \pm 2.23$ & - \\
\hline
\end{tabular}

$A U C_{0-6}$ the area under the concentration-time curve between 0 and $6 \mathrm{~h}, C_{\max }$ maximum plasma concentration, $C_{\min }$ minimum plasma concentration, $k_{10}$, the rate at which the drug leaves the system from the central compartment, $k_{12}$ intercompartment transfer rate constant from compartment $\mathrm{X}_{1}$ to $\mathrm{X}_{2}, k_{21}$ intercompartment transfer rate constant from compartment $\mathrm{X}_{2}$ to $\mathrm{X}_{1}, t_{1 / 2 \alpha}$ distribution half-life, $t_{1 / 2 \beta}$ elimination half-life, VAP ventilator-associated pneumonia, $V_{d}$ volume of distribution at steady state

${ }^{\mathrm{a}} p<0.05$ versus patients during support with ECMO

${ }^{b}$ Data from our 3 previous studies in 13 critically ill patients with VAP [13, 14] and 5 serious bacteremia in immunocompromised patients with febrile neutropenia [15]

${ }^{c}$ Data from our previous study in 8 healthy volunteers [16]

the ECMO circuit flows. All recruited patients had APACHE II scores of $\geq 19$ and SOFA scores of $\geq 10$ and one-half of them were experiencing renal dysfunction, as defined by $\mathrm{CL}_{\mathrm{cr}}$ values of $\leq 60 \mathrm{~mL} / \mathrm{min}$. Moreover, all enrolled patients had hypoalbuminemia due to decreased protein synthesis in the liver and were receiving several concomitant medications, particularly inotropic agents for the treatment of shock. Studies in animal infection models have found that bactericidal effects of carbapenems against Escherichia coli and $P$. aeruginosa in a murine thigh infection model were observed when plasma drug concentrations were above the MIC for $40 \%$ of the dosing interval [24]. However, for life-threatening severe infections in immunocompromised hosts, the $f \mathrm{~T}_{>\text {MIC }}$ target required for sufficient bactericidal effects are increased to almost $100 \%$ [25-27]. By referral to the European Committee on Antimicrobial Susceptibility Testing MIC distributions, the epidemiological cut-offs for $P$. aeruginosa and A. baumannii were 4 and $1 \mathrm{mg} / \mathrm{L}$, 


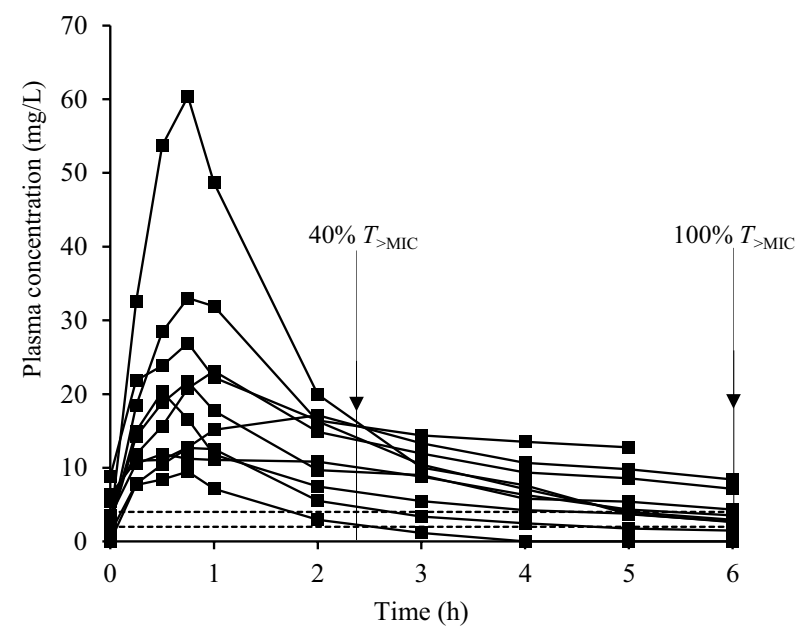

Fig. 1 The individual plasma concentration-time profiles of imipenem in 10 critically ill patients with severe infections during support with extracorporeal membrane oxygenation. The broken lines represent the MICs of 2 and $4 \mathrm{mg} / \mathrm{L}$. MIC minimal inhibitory concentration, $T_{>\text {MIC }}$ time during which the drug concentration remains above the MIC

respectively. By referral to the Clinical and Laboratory Standards Institute, the MIC breakpoints for $P$. aeruginosa and Acinetobacter spp. were 4 and $2 \mathrm{mg} / \mathrm{L}$, respectively. In the current study, we found that the plasma concentrations of imipenem $40 \% T_{>\mathrm{MIC}}$ for MICs of 2 and $4 \mathrm{mg} / \mathrm{L}$ and $100 \% T_{>\text {MIC }}$ for a MIC of $2 \mathrm{mg} / \mathrm{L}$ could be achieved in most patients, whereas only some patients could achieve $100 \%$ $T_{>\text {MIC }}$ for a MIC of $4 \mathrm{mg} / \mathrm{L}$. Therefore, high dosage recommendation of imipenem should be required for coverage of highly resistant microorganisms in life-threatening severe infections during support with ECMO.

The current study had a few limitations that must be considered. First, the number of enrolled patients was small and not case-control matched with critically ill patients without ECMO support. Therefore, further large, well-designed clinical trials to determine the effect if any of ECMO on the pharmacokinetic parameters of imipenem in this patient population are required. Second, the population pharmacokinetics of imipenem were not analyzed and a Monte Carlo simulation was not performed to determine the effects of different dosing approaches.

\section{Conclusion}

Pathophysiological changes in critically ill patients with severe infections during support with ECMO had a greater impact on altered pharmacokinetic patterns of imipenem than those that occur in critically ill patients without ECMO support. Therefore, the largest licensed dose, $1 \mathrm{~g}$ every $6 \mathrm{~h}$, of imipenem, may be required to maintain adequate drug concentrations to achieve the pharmacokinetic/pharmacodynamic targets for effective antimicrobial therapy in this patient population.

Acknowledgements The authors thank Mr David Patterson for English proofreading of the manuscript.

\section{Compliance with Ethical Standards}

Funding This work was supported by a grant from the Faculty of Medicine, Prince of Songkla University, Thailand.

Conflicts of interest Sutep Jaruratanasirikul, Veerapong Vattanavanit, Maseetoh Samaeng, Monchana Nawakitrangsan and Somchai Sriwiriyajan have no conflicts of interest that are relevant to the content of this paper.

Ethical approval All procedures performed in studies involving human participants were in accordance with the study protocol, the Ministerial Ordinance on GCP for Drugs, and with the 1964 Helsinki Declaration and its later amendments or comparable ethical standards. The study protocol (code EC-56-065-14-1-1) was approved by the IRB at Songklanagarind Hospital on 17 December 2012.

Informed consent Informed consent was obtained from each subject's legally acceptable representative before enrollment.

\section{References}

1. Sherwin J, Heath T, Watt K. Pharmacokinetics and dosing of anti-infective drugs in patients on extracorporeal membrane oxygenation: a review of the current literature. Clin Ther. 2016;38(9):1976-94.

2. Honoré PM, Jacobs R, Spapen HD. Antimicrobial dosing during extracorporeal membrane oxygenation. In: Vincent JL, editor. Annual update in intensive care and emergency medicine 2014. New York: Springer; 2014. p. 43-52.

3. Shekar K, Fraser JF, Smith MT, Roberts JA. Pharmacokinetic changes in patients receiving extracorporeal membrane oxygenation. J Crit Care. 2012;27(6):741.e9-18.

4. Hahn J, Choi JH, Chang MJ. Pharmacokinetic changes of antibiotic, antiviral, antituberculosis and antifungal agents during extracorporeal membrane oxygenation in critically ill adult patients. J Clin Pharm Ther. 2017;42(6):661-71.

5. Rodloff AC, Goldstein EJC, Torres A. Two decades of imipenem therapy. J Antimicrob Chemother. 2006;58(5):916-29.

6. Balfour JA, Bryson HM, Brogden RN. Imipenem/Cilastatin: an update of its antibacterial activity, pharmacokinetics and therapeutic efficacy in the treatment of serious infections. Drugs. 1996;51(1):99-136.

7. Craig WA. Interrelationship between pharmacokinetics and pharmacodynamics in determining dosage regimens for broad spectrum cephalosporins. Diagn Microbiol Infect Dis. 1995;22(1-2):89-96.

8. Vogelman B, Gudmundsson S, Leggett J, Turnidge J, Ebert S, Craig WA. Correlation of antimicrobial pharmacokinetic parameters with therapeutic efficacy in an animal model. J Infect Dis. 1988;158(4):831-47. 
9. Welsch C, Augustin P, Allyn J, Massias L, Montravers P, Allou $\mathrm{N}$. Alveolar and serum concentrations of imipenem in two lung transplant recipients supported with extracorporeal membrane oxygenation. Transpl Infect Dis. 2015;17(1):103-5.

10. Garcia-Capdevila L, López-Calull C, Arroyo C, Moral MA, Mangues MA, Bonal J. Determination of imipenem in plasma by highperformance liquid chromatography for pharmacokinetic studies in patients. J Chromatogr B. 1997;692(1):127-32.

11. Swanson DJ, DeAngelis C, Smith IL, Schentag JJ. Degradation kinetics of imipenem in normal saline and in human serum. Antimicrob Agents Chemother. 1986;29(5):936-7.

12. FDA. US department of health and human services. In: Draft guidance for industry: bioanalytical method validation. 2013. http:// www.fda.gov/downloads/Drugs/GuidanceComplianceRegulat oryInformation/Guidance/UCM368107.pdf. Accessed 21 Jan 2013.

13. Jaruratanasirikul S, Sudsai T. Comparison of the pharmacodynamics of imipenem in patients with ventilator-associated pneumonia following administration by 2 or $0.5 \mathrm{~h}$ infusion. J Antimicrob Chemother. 2009;63(3):560-3.

14. Jaruratanasirikul S, Wongpoowarak W, Nawakitrangson M, Thengyai S, Samaeng M. Population pharmacokinetics and Monte Carlo dosing simulations of imipenem in patients with ventilatorassociated pneumonia. Lung Breath J. 2017;1(1):1-4.

15. Jaruratanasirikul S, Wongpoowarak W, Jullangkoon M, Samaeng M. Population pharmacokinetics and dosing simulations of imipenem in serious bacteraemia in immunocompromised patients with febrile neutropenia. J Pharmacol Sci. 2015;127(2):164-9.

16. Jaruratanasirikul S, Raungsri N, Punyo J, Sriwiriyajan S. Pharmacokinetics of imipenem in healthy volunteers following administration by $2 \mathrm{~h}$ or $0.5 \mathrm{~h}$ infusion. $\mathrm{J}$ Antimicrob Chemother. 2005;56(6):1163-5.

17. Robert S, Munford RS, Suffredini AF. Sepsis, severe sepsis, and septic shock. In: Mandell GL, Bennett JE, Dolin R, editors. Mandell, Douglas, and Bennett's principles and practice of infectious diseases. Philadelphia: Churchill Livingstone Elsevier; 2015. p. 914-34.
18. Taccone FS, Hites M, Beumier M, Scolletta S, Jacobs F. Appropriate antibiotic dosage levels in the treatment of severe sepsis and septic shock. Curr Infect Dis Rep. 2011;13(5):406-15.

19. Varghese JM, Roberts JA, Lipman J. Antimicrobial pharmacokinetic and pharmacodynamic issues in the critically ill with severe sepsis and septic shock. Crit Care Clin. 2011;27(1):19-34.

20. Shekar K, Roberts JA, Mcdonald C, Ghassabian S, Anstey C, Wallis SC, et al. Protein-bound drugs are prone to sequestration in the extracorporeal membrane oxygenation circuit: results from an ex vivo study. Crit Care. 2015;19:164.

21. Donadello K, Antonucci E, Cristallini S, Roberts JA, Beumier M, Scolletta $S$, et al. $\beta$-Lactam pharmacokinetics during extracorporeal membrane oxygenation therapy: a case-control study. Int J Antimicrob Agents. 2015;45(3):278-82.

22. Shekar K, Fraser JF, Taccone FS, Welch S, Wallis SC, Mullany $\mathrm{DV}$, et al. The combined effects of extracorporeal membrane oxygenation and renal replacement therapy on meropenem pharmacokinetics: a matched cohort study. Crit Care. 2014;18(6):565.

23. Viaene E, Chanteux H, Servais H, Mingeot-Leclercq MP, Tulkens PM. Comparative stability studies of antipseudomonal betalactams for potential administration through portable elastomeric pumps (home therapy for cystic fibrosis patients) and motor-operated syringes (intensive care units). Antimicrob Agents Chemother. 2002;46(8):2327-32.

24. Drusano GL. Prevention of resistance: a goal for dose selection for antimicrobial agents. Clin Infect Dis. 2003;36(Suppl 1):S42-50.

25. Ariano RE, Nyhlén A, Donnelly JP, Sitar DS, Harding GKM, Zelenitsky SA. Pharmacokinetics and pharmacodynamics of meropenem in febrile neutropenic patients with bacteremia. Ann Pharmacother. 2005;39(1):32-8.

26. Mouton JW, Touw DJ, Horrevorts AM, Vinks AATMM. Comparative pharmacokinetics of the carbapenems: clinical implications. Clin Pharmacokinet. 2000;39(3):185-201.

27. Turnidge JD. The pharmacodynamics of beta-lactams. Clin Infect Dis. 1998;27(1):10-22. 